\title{
Relief of postoperative pain with jaw relaxation, music and their combination
}

\author{
Marion Good ${ }^{\mathrm{a}, *}$, Michael Stanton-Hicks ${ }^{\mathrm{b}}$, Jeffrey A. Grass ${ }^{\mathrm{b}}$, Gene Cranston Anderson ${ }^{\mathrm{a}}$, \\ Charles Choi ${ }^{c}$, Laree J. Schoolmeesters ${ }^{\mathrm{a}}$, Ali Salman ${ }^{\mathrm{a}}$ \\ ${ }^{a}$ Frances Payne Bolton School of Nursing, Case Western Reserve University, 10900 Euclid Avenue, Cleveland, OH 44106-4904, USA \\ ${ }^{\mathrm{b}}$ The Cleveland Clinic Foundation, 9500 Euclid Avenue, Cleveland, OH 44106, USA \\ ${ }^{\mathrm{c}}$ Fairview Health System, 18101 Lorain Avenue, Cleveland, OH 44111, USA
}

Received 11 September 1998; received in revised form 3 December 1998; accepted 24 December 1998

\begin{abstract}
The aim of this randomized controlled trial was to determine the effect of jaw relaxation, music and the combination of relaxation and music on postoperative pain after major abdominal surgery during ambulation and rest on postoperative days 1 and 2 . Opioid medication provided for pain, following abdominal surgery, does not always give sufficient relief and can cause undesired side effects. Thus, additional interventions such as music and relaxation may provide more complete relief. Previous studies have found mixed results due to small sample sizes and other methodological problems. In a rigorous experimental design, 500 subjects aged 18-70 in five Midwestern hospitals were randomly assigned by minimization to a relaxation, music, relaxation plus music, or control group. Interventions were taught preoperatively and tested postoperatively. The same amount of time was spent with subjects in the control group. Pain was measured with the visual analogue sensation and distress of pain scales. Demographic and surgical variables, and milligrams of parenteral or oral opioids in effect at the time of testing were not significantly different between the groups, nor did they correlate with pain scores. Controlling for pretest sensation and distress, orthogonal a priori contrasts and multivariate analysis of covariance indicated that the three treatment groups had significantly less pain than the controls, $(P=0.028-0.000)$ which was confirmed by the univariate analysis of covariance $(P=0.018-0.000)$. Post hoc multivariate analysis revealed that the combination group had significantly less sensation and distress of pain than the control group on all post-tests $(P=0.035-0.000)$, and the relaxation and music groups had significantly less on all tests $(P=0.022-0.000)$ except after ambulation. At post ambulation those using relaxation did not have significantly less pain than the controls on both days and those using music did not on day 1 , although there were some univariate effects. A corresponding significant decrease in mastery of the interventions from pre to post ambulation suggests the need for reminders to focus on the intervention during this increased activity. Physicians and nurses preparing patients for surgery and caring for them afterward, should encourage patients to use relaxation and music as adjuvants to medication for postoperative pain. (C) 1999 International Association for the Study of Pain. Published by Elsevier Science B.V.
\end{abstract}

Keywords: Pain; Music; Relaxation

\section{Introduction}

Each year in the United States, 23 million people undergo surgical operations and experience postoperative pain (Chapman, 1985). The pain increases stress responses, which in turn increase tissue breakdown metabolism, coagulation and fluid retention, with deleterious effects on recovery. Pain also interferes with appetite and sleep, and it can contribute to complications, prolonging hospitaliza-

\footnotetext{
* Corresponding author. Tel.: +1-216-368-5975; fax: +1-216-368-3542; e-mail: mpg@po.cwru.edu
}

tion (Acute Pain Management Guideline Panel, 1992; Miaskowski, 1993).

Even with medication, most postoperative patients report moderate to severe pain at rest that increases during ambulation (Bonica, 1983; Weis et al., 1983). After activity ceases, pain may continue but more medication may be unavailable, since it can only be given at prescribed intervals. Some patients may be especially sensitive to pain, or have insufficient response to medication. Others may wish to avoid the side effects of increased doses of opioids.

Relaxation and music have been recommended as adjuvants to medication. Both act on pain by decreasing anxiety 
(Borkovec and Sides, 1979; Hanser et al., 1983), lowering muscle tension and distracting attention (Good, 1995), thereby affecting the central control processes that modulate pain transmission. Relaxation directs the mind to concentrate on relaxing muscles, breathing evenly and reducing thoughts. Music is composed of auditory tones and rhythms that do not direct the mind but distract it, and they relax the body as well. Music can focus attention, facilitate breathing and stimulate the relaxation response (Livingston, 1979).

Some studies have found that relaxation and music reduced pain, but in others results have been mixed due to small samples and other methodological problems, including lack of random assignment, lack of control for pretest pain, and little practice or assurance that subjects had mastered the techniques (Blankfield, 1991; Henry, 1995; Stevenson, 1995; Good, 1996; Sears and Carroll, 1998). In some studies relaxation or music reduced reports of sensory and affective pain (Flaherty and Fitzpatrick, 1978; Lawlis et al., 1985; Levin et al., 1987; Mullooly et al., 1988; Miller and Perry, 1990), while in others they reduced only affective pain (Wells, 1982; Horowitz et al., 1984; Mogan et al., 1985), had different results on different measures of pain (Good and Chin, 1998), or on different postoperative days (Good, 1995; Good and Chin, 1998). In other studies relaxation or music had no effect on pain but reportedly, provided a relaxing and pleasant experience (Heitz et al., 1992; Zimmerman et al., 1996; Heiser et al., 1997).

As a result, the usefulness of these interventions remains unclear. In the randomized controlled trial reported here, jaw relaxation, music and the combination of relaxation and music were compared at ambulation and rest in a large sample with optimum control.

\section{Methods}

\subsection{Sample}

An experimental pretest-post-test design, was used to study 617 subjects recruited from three tertiary care medical centers and two suburban community hospitals in a large Midwestern city over a period of 29 months. All patients spoke English, were scheduled for major abdominal surgery, and were expected to use patient controlled analgesia (PCA), and to ambulate after surgery. Patients with laparoscopic or vaginal surgery, epidural analgesia, or a diagnosis of psychosis, mental retardation, or opioid dependence were excluded. The study was approved by the investigational review board of each institution and all patients provided informed written consent preoperatively.

A convenience sample of subjects was selected from the pre-admission testing appointment schedules of the five hospitals. After an interview, a computerized minimization program (Zeller et al., 1997) was used to randomly assign them to a control group receiving usual care, three experimental groups, relaxation, music and combination, and two testing sequences, ambulation first or rest first. The program controlled for gender, surgical specialty, intestinal surgery, chronic pain, first surgery and antidepressant/benzodiazepine use. Of the total sample, $165(27 \%)$ were assigned to the relaxation group, $151(25 \%)$ to the music group, 149 (24\%) to the combination group, and 152 (25\%) to the control group. Half of the subjects were randomly assigned to be tested at ambulation first $(n=318,52 \%)$ and half to be tested at rest first $(n=299,49 \%)$. There were no significant differences in the number of subjects assigned to each treatment group, $X^{2}(3, N=617)=1.03, P=0.79$, or to each testing sequence, $X^{2}(1, N=617)=0.21, P=0.65$.

After surgery, $76(12 \%)$ subjects no longer qualified for the study, and 33 (5\%) withdrew. Reasons for disqualification were epidural anesthesia, surgery changed or canceled, and illness or other factors. Reasons for withdrawal were that patients did not feel well, did not want to use the treatment $(n=8)$, wanted to rest, or provided no reason. Thus there were 500 subjects in the final sample. The number of subjects withdrawing did not significantly differ in the four groups, $X^{2}(3, N=33)=4.21, P=0.24$, or between the two testing sequences, $X^{2}(1, N=33)=3.67, P=0.06$, or between sequences per group, $X^{2}(3, N=33)=1.09, P=$ 0.78 .

Two hundred twenty-one (44\%) subjects in the final sample missed at least one test, and $28(6 \%)$ missed more than one test. Reasons for a missed test were adverse symptoms $(n=80)$, condition at time of test $(n=36)$, refusal to ambulate $(n=41)$, early discharge $(n=14)$, too much pain ( $n=10)$, did not like the music $(n=31)$, and miscellaneous or no reason given $(n=37)$. Those who had complete data for at least one of the four tests were included in the analysis (Everitt and Dunn, 1991). On Day 1, there were 340 subjects tested during ambulation, and 458 at rest; on Day 2, there were 401 were tested during ambulation and 443 at rest.

In the final sample, there were $87(17 \%)$ men and 413 $(83 \%)$ women; $350(70 \%)$ were from the three tertiary care centers, and $150(30 \%)$ from the two community hospitals. Their mean age was $45.37(\mathrm{SD}=11.03)$, range 20 to 70 years and the majority were Caucasian $(81 \%)$, Protestant $(52 \%)$, married $(61 \%)$, employed $(69 \%)$, had completed a year or more of college $(64 \%)$, and had a monthly household income of 3000 US $\$$ or less $(57 \%)$. Over half smoked $(52 \%)$, and most had previous surgery (94\%), did not drink alcohol (86\%), and did not have chronic pain $(64 \%)$, or take benzodiazepines or antidepressants $(85 \%)$, or steroids $(89 \%)$. The mean body mass for the sample was 28.84 $\mathrm{kg} / \mathrm{m}^{2}, \mathrm{SD}=7.94$. The final sample underwent gynecological $(50 \%)$, gastro-intestinal $(28 \%)$, exploratory $(18 \%)$ and urinary surgery (4\%). Subjects spent an average of $3 \mathrm{~h} 15$ $\min ,(\mathrm{SD}=1 \mathrm{~h} 8 \mathrm{~min})$ in surgery. During surgery, cancer was found in $19 \%$. The majority of surgical incisions were in the lower abdomen (62\%); with 54\% vertical incisions, and $35 \%$ horizontal. Most subjects (93\%) received initial postoperative orders for PCA with a lockout range of 5 to 10 min, but $4 \%$ received intramuscular analgesics as needed, 
$2 \%$ intravenous opioids, and $1 \%$ other routes. A few (13\%) progressed to oral medication by the first postoperative day, and $35 \%$ more by day 2 , for a total of $48 \%$ by day 2 .

There were $26 \%$ subjects receiving relaxation, $26 \%$ receiving music, $24 \%$ receiving the combination, and $24 \%$ in the control group, $X^{2}(3, N=500)=0.40, P=0.94$. On day 1 within each group, half were tested first during ambulation and half were tested first during rest; the order was reversed on day $2, X^{2}(1, N=500)=0, P=0.84$.

\subsection{Experimental interventions}

The interventions, jaw relaxation, music, or a combination of relaxation and music, were taught preoperatively with an introductory tape using earphones, and tested with a treatment tape postoperatively during ambulation and at rest on days 1 and 2. To control for variations in hospital practice, all subjects received instruction in getting out of bed and splinting their incision while ambulating. To control for expectations and prevent demoralization, the control subjects were told that this was the treatment they were assigned to receive and that an important purpose of the research was to compare pain during ambulation and at rest. To prevent diffusion of treatments, room assignments were controlled so that subjects were not assigned to the same room. To prevent extraneous variation in the four groups, a similar amount of time was allotted for instruction, experimenter contact and validation of effectiveness.

Subjects in the relaxation group used the following protocol: let the lower jaw drop slightly as though starting a small yawn; keep the tongue quiet and resting in the bottom of the mouth; let the lips get soft; breathe slowly and rhythmically with a three-rhythm pattern of inhale, exhale and rest; stop forming words; do not even think words (Flaherty and Fitzpatrick, 1978). An introductory tape used preoperatively explained the purpose and effects of relaxation and described the jaw relaxation technique; subjects then practiced the technique and were coached by the data collector. Postoperatively, subjects used an intervention tape in which the relaxation technique was repeated at 1-min intervals.

The music intervention began preoperatively when subjects listened to a half-minute excerpt of each type of music. Subjects chose one of five types of taped soothing music: synthesizer, harp, piano, orchestral or slow jazz. They listened to it while the data collector coached and reinforced them on letting the music distract or relax (Good, 1995).

The preoperative combination tape consisted of the procedures of both the music and relaxation groups. Postoperatively, the combination group listened to a tape on which the relaxation technique was repeated occasionally with the chosen music playing continuously in the background. In the combination and music groups, 73 (29\%) chose orchestral music, 60 (24\%) chose piano, 60 (24\%) chose jazz, 33 (13\%) chose synthesizer, and $24(10 \%)$ chose harp.

Preoperatively subjects practiced twice with the introductory tape while sitting in a chair, and then twice with the intervention tape, first while sitting and then while getting up and walking. Subjects' ability to use the techniques was verified using four criteria during preoperative practice and postoperative testing: (a) face relaxed (b) no grimace or frown (c) not talking (d) slow respirations. Each criteria was observed at specific points in the procedure and given two points if it was present, and one point if it was not. Mastery was defined as a score of seven out of eight points.

The control group received the same procedures and measures as the treatment groups, but did not receive a tape. Ten minutes of casual conversation took the place of the introductory tape. During the rest condition, the control group was asked to lie quietly $15 \mathrm{~min}$.

\subsection{Measurements}

\subsubsection{Sensation and distress of pain}

Postoperative pain is defined as an unpleasant sensory and affective experience. The sensory component of pain, defined as the unpleasant, physical perception of hurt, was measured with the sensation of pain visual analogue scale (VAS). The affective component of pain, defined as the amount of emotional distress associated with the sensation, was measured by a VAS distress scale at the same data points. Pain is conceptualized in this study as a composite of sensory and affective pain. The two scales, adapted from Johnson (1973), were 100-mm lines with verbal anchors of 'none' to 'most sensation' and 'most distress'. The scales were introduced preoperatively and were then used to determine the intensity of past and expected sensation, and distress of pain. Postoperatively they were used before and after a $15 \mathrm{~min}$ rest period and at four points during ambulation on postoperative days 1 and 2 (before preparation, after preparation, after ambulation and after recovery). The preparatory measure was considered the pretest; all other measurements were post-tests.

Construct validity of the original scales was supported by Johnson (1973), who found that subjects could differentiate between sensation and distress during induced ischemic pain. Concurrent validity, comparing post ambulatory scores on the original scales to scores on the Melzack (1975) McGill Pain Questionnaire's Pain Rating ScaleRanked, indicated strongly positive correlations for sensation $(r=0.44, P<0.001)$, and distress of pain $(r=0.55$, $P<0.001)$ (Good, 1995). In the present study, correlations of the scores during rest on the original Johnson scales with the VAS sensation and distress scales ranged from $r=0.89$ to $r=0.92$. The reliability of these single-item measures of changeable states has not been established.

\subsubsection{Opioid intake}

To examine the confounding effects of analgesic medication, the milligrams of opioid intake during tests at ambulation and rest were calculated by subtracting the total milligrams on the PCA display screen just before the test from the total after the test. For those receiving other par- 
enteral or oral opioid medications, the presence of opioid 'on board' (i.e. in effect) was recorded if the drug had been given before testing within the prescribed interval.

\subsection{Procedure}

\subsubsection{Preoperative instruction}

Names of patients scheduled for major abdominal surgery were obtained each day by reviewing the appointment schedule in the preadmission testing (PAT) departments of the five hospitals. A data collector met patients after their PAT appointment, obtained written informed consent, randomly assigned and interviewed them to obtain demographic and other data on variables that might affect postoperative pain such as past pain, expected pain, smoking and alcohol use. Subjects were taught use of the sensation and distress scales; and then they listened to the intervention teaching tapes.

\subsubsection{Postoperative testing}

Postoperatively, patients' charts were reviewed to determine the surgical procedure, postoperative diagnosis, length of surgery and amount of analgesic, sedative, or steroid medication in effect at the time of measurement. Ninety percent of the testing was done between the hours of 0930 and $1545 \mathrm{~h}$, at a time agreeable to subjects. To reduce confounding, testing on day 1 was done at the second ambulation after surgery rather than the first. To reduce carryover effects, testing during ambulation and rest were performed at least $1 \mathrm{~h}$ apart. On day 1 after surgery, the data collector came to the bedside and brought the tape and tape player to experimental subjects for testing during the assigned condition, ambulation or rest.

Testing at ambulation consisted of three phases: a 5-min preparatory period in bed; an ambulation period which included getting out of bed, walking a comfortable distance, and returning to bed; and a 10-min recovery period in bed. Those in the treatment groups listened to the tape throughout all three phases. Subjects in all four groups were accompanied by a nurse data collector. In all subjects, the data collector measured sensation and distress four times during ambulation: before and after the 5-min preparatory period, after ambulation, and after the 10-min recovery from ambulation. Ambulation lasted $M=27, \mathrm{SD}=15 \mathrm{~min}$ and $M=26$, $\mathrm{SD}=7$ min on days 1 and 2 , respectively.

During the rest condition, the data collector measured sensation and distress before and after the 15 min treatment tape or control condition of resting in bed. On Day 2, the procedures for ambulation and rest were repeated with the order of activity reversed. PCA opioid analgesics were not restricted, but the data collector checked the PCA pump before and after each treatment, and noted other analgesics in effect from the chart.

\subsection{Analysis}

To identify potentially confounding covariates (at $r>$
0.30) (Cook and Campbell, 1979), Pearson's product moment correlations were calculated between the measures of pain and possible covariates. Multivariate analysis of covariance (MANCOVA), controlling for identified covariates, was then used to compare post-test pain at ambulation and rest with three orthogonal a priori contrasts: (1) the three treatment groups versus the control group (2) the combination group versus the single treatment groups, relaxation and music (3) the relaxation group versus the music group. The level of significance was set at 0.05 . To determine whether univariate (UV) analysis confirmed the multivariate (MV) results, analysis of covariance (ANCOVA) was used, controlling for the corresponding pretest.

\section{Results}

Mean scores for pain sensation and distress for the four groups during ambulation and rest on both days are shown in Table 1 and Fig. 1. At every point after the preparatory pretest, the control group had higher raw scores on sensation and distress than any of the treatment groups.

\subsection{Equality of groups and identification of covariates}

One-way ANOVA determined that at the pretest (preparatory) measurement there were no significant betweengroup differences in sensation and distress, except for sensation before rest on day $2, F(3,439)=2.41, P=0.033$. Also, the following possible confounding variables were not correlated with dependent measures and there were no significant group differences in them: age, gender, marital status, education, smoking, alcohol use, chronic pain, preoperative belief in intervention effectiveness for pain, number of previous surgeries, intensity of past or expected sensation or distress, past use of a relaxation technique, hours in surgery, incision length, location, or direction, PCA milligrams of morphine equivalent used during each test and number of subjects with PCA or other opioids on board. Only pretest sensation and distress scores were correlated with ambulation and rest post-test scores and thus were used as covariates, $r=0.44-0.86$, all $P=0.000$.

\subsection{Overall multivariate contrasts}

While controlling for pretest sensation and distress, MANCOVA using orthogonal a priori contrasts indicated that on contrast 1 the three treatment groups taken together had significantly less post-test pain than the controls at all post-tests during ambulation and rest on both days (Table 2). Comparison of the combination group to the relaxation and music groups together on contrast 2 indicated that only at day 1 rest did subjects using the combination have significantly less post-test pain than those using the individual treatments of relaxation and music, $F(2,451)=2.96, P=$ 0.027 . On contrast 3 no significant difference was found 
Table 1

Group means and standard deviations of sensation and distress scores $(N=500)$

\begin{tabular}{|c|c|c|c|c|c|c|c|c|}
\hline \multirow[b]{2}{*}{ Data points } & \multicolumn{4}{|l|}{ Day 1} & \multicolumn{4}{|l|}{ Day 2} \\
\hline & $\begin{array}{l}\text { Relaxation } \\
n=82^{\mathrm{a}}, 116^{\mathrm{b}} \\
\mathrm{M} \pm(\mathrm{SD})\end{array}$ & $\begin{array}{l}\text { Music } \\
n=89,122 \\
M \pm(S D)\end{array}$ & $\begin{array}{l}\text { Combination } \\
n=80,109 \\
\mathrm{M} \pm(\mathrm{SD})\end{array}$ & $\begin{array}{l}\text { Control } \\
n=89,111 \\
\mathrm{M} \pm(\mathrm{SD})\end{array}$ & $\begin{array}{l}\text { Relaxation } \\
n=98,109 \\
\mathrm{M} \pm(\mathrm{SD})\end{array}$ & $\begin{array}{l}\text { Music } \\
n=100,118 \\
\mathrm{M} \pm(\mathrm{SD})\end{array}$ & $\begin{array}{l}\text { Combination } \\
n=97,107 \\
M \pm(S D)\end{array}$ & $\begin{array}{l}\text { Control } \\
n=106,109 \\
\mathrm{M} \pm(\mathrm{SD})\end{array}$ \\
\hline \multicolumn{9}{|l|}{ Sensation } \\
\hline \multicolumn{9}{|l|}{ Ambulation } \\
\hline Preparatory & $43(25)$ & $45(25)$ & $44(24)$ & $38(25)$ & $34(25)$ & $33(26)$ & $34(23)$ & $33(24)$ \\
\hline Post preparatory & $32(23)$ & $36(26)$ & $36(24)$ & $39(25)$ & $28(24)$ & $27(24)$ & $29(22)$ & $33(24)$ \\
\hline Post ambulation & $47(26)$ & $44(27)$ & $45(26)$ & $47(24)$ & $37(24)$ & $32(26)$ & $32(23)$ & $37(26)$ \\
\hline Post recovery & $33(25)$ & $34(26)$ & $35(25)$ & $38(25)$ & $26(23)$ & $25(24)$ & $25(20)$ & $30(24)$ \\
\hline \multicolumn{9}{|l|}{ Rest } \\
\hline Pre rest & $45(26)$ & $45(27)$ & $47(25)$ & $44(25)$ & $36(25)$ & $35(25)$ & $31(22)$ & $29(22)$ \\
\hline Post rest & $34(26)$ & $33(26)$ & $32(21)$ & $39(26)$ & $27(22)$ & $25(23)$ & $22(20)$ & $29(23)$ \\
\hline \multicolumn{9}{|l|}{ Distress } \\
\hline \multicolumn{9}{|l|}{ Ambulation } \\
\hline Preparatory & $35(26)$ & $38(28)$ & $38(25)$ & $36(26)$ & $32(28)$ & $30(28)$ & $30(24)$ & $32(25)$ \\
\hline Post preparatory & $27(24)$ & $31(27)$ & $30(25)$ & $38(26)$ & $25(24)$ & $24(24)$ & $24(21)$ & $31(24)$ \\
\hline Post ambulation & $39(28)$ & $37(27)$ & $38(28)$ & $45(26)$ & $31(25)$ & $29(26)$ & $27(23)$ & $34(26)$ \\
\hline Post recovery & $25(23)$ & $29(27)$ & $28(25)$ & $34(26)$ & $22(25)$ & $21(24)$ & $22(20)$ & $27(24)$ \\
\hline \multicolumn{9}{|l|}{ Rest } \\
\hline Pre rest & $42(29)$ & $38(28)$ & $42(27)$ & $42(30)$ & $32(27)$ & $31(26)$ & $27(24)$ & $27(23)$ \\
\hline Post rest & $30(27)$ & $28(26)$ & $26(21)$ & $36(28)$ & $23(22)$ & $23(24)$ & $19(20)$ & $28(25)$ \\
\hline
\end{tabular}

${ }^{\mathrm{a}} n$ at ambulation.

${ }^{\mathrm{b}} n$ at rest.

between the relaxation and music groups on any test. ${ }^{1}$ Univariate ANCOVA confirmed the multivariate analyses on contrasts 1 and 2 (Table 2).

\subsection{Effect on pain: overall multivariate post-hoc results}

Post-hoc MANCOVA showed that each treatment group had significantly less pain than the control group (Table 3 ). Persons who used relaxation had significantly less pain than the controls on six of the eight post-tests; the exceptions were the post ambulation tests on days 1 and 2. Persons who used music had significantly less pain than the control group at seven post-tests, the only exception being the postambulation test on day 2. However, persons who used the combination tape had significantly less pain than the controls on all tests. In contrast 2 post-hoc MV tests comparing the combination group to either the relaxation $F(2,220)=$ $2.31, P=0.051$, or the music group $F(2,226)=1.88, P=$ 0.078 , did not reach significance at day 1 rest.

\subsection{Effect on sensation or distress: univariate post-hoc results}

Post-hoc UV ANCOVA of sensation and distress on contrast 1 (Table 3) confirmed the MV post-hoc analyses for all

\footnotetext{
${ }^{1}$ Similar results were found using multivariate contrasts with the 285 subjects who completed all four tests.
}

treatment versus control group tests except for two mixed examples of Rao's paradox. After ambulation on day 1, sensation did not significantly differ between the relaxation group and the controls, $P=0.172$, but distress did, $P=0.035$. On day 2 after ambulation, distress did not significantly differ between the music group and controls, $P=0.051$, but sensation did, $P=0.013$. In each paradox, the significant UV factor was not strong enough to carry the other to MV significance, but it was present.

The UV post-hoc analysis of covariance comparing the combination versus the individual interventions at day 1 rest failed to confirm the non-significant MV post-hoc analyses; significance was found on three of the four tests. Compared with the relaxation group, the combination had significantly less sensation $F(1,228)=3.75, P=0.027$, and less distress, $F(1,222)=3.84, P=0.026$; however, compared with the music group, the combination had significantly less distress, $F(1,222)=4.06, P=0.023$, but the lower sensation score was not significant. Three independent differences are there, but fail to carry the post-hoc MV test to significance.

\subsection{Magnitude of differences}

The magnitude of differences in means between treatment and control groups is of clinical interest. Significant mean differences between treatment and control groups, adjusted for pretests, ranged from $3.64 \mathrm{~mm}$ for sensation and $4.21 \mathrm{~mm}$ for distress on day 2 post ambulation to 8.12 
A

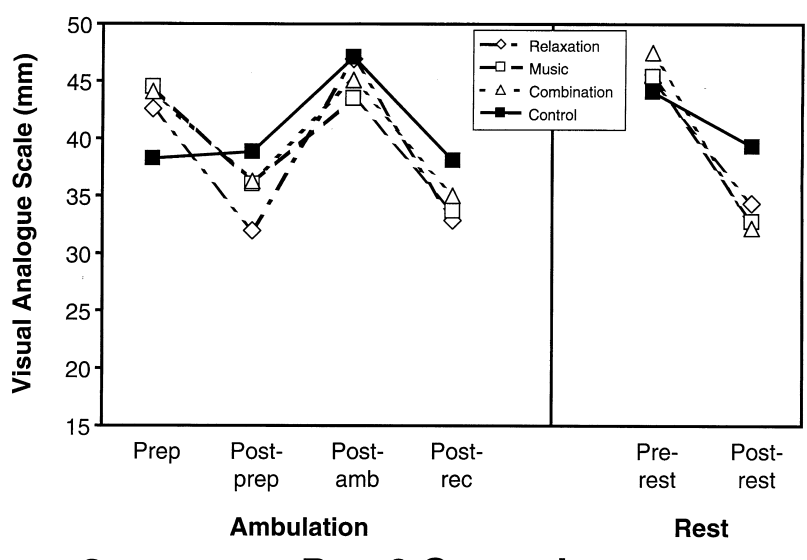

C

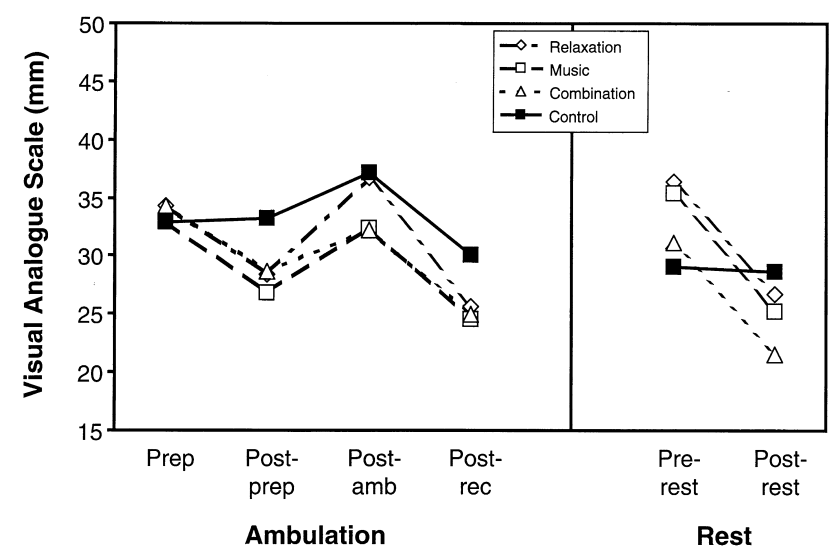

B

Day 1 Distress

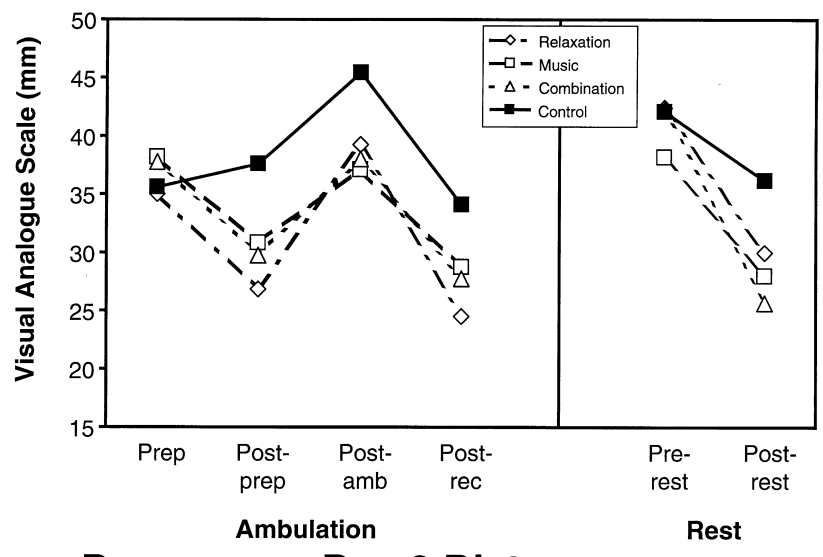

D

Day 2 Distress

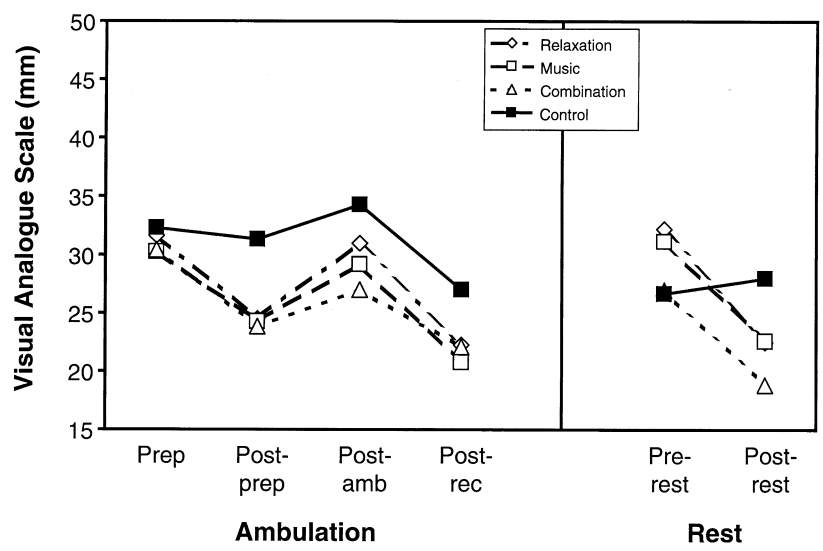

Fig. 1. Mean sensation and distress scores at ambulation and rest on postoperative day 1 and 2 using 100 mm visual analogue scales. The preparatory measure was the pretest; sensation and distress were then measured at three post-tests during ambulation (post preparatory, post ambulation, post recovery), and once following rest (post rest). Prep, preparatory (pretest) measure; Post-prep, after 5 min preparation for ambulation; Post-amb, after ambulation; Post-rec, after 10 min recovery from ambulation.

$\mathrm{mm}$ for sensation and $9.81 \mathrm{~mm}$ for distress on day 1 post preparatory. Differences at day 1 post ambulation, were $5.08 \mathrm{~mm}$ for sensation and $8.13 \mathrm{~mm}$ for distress. At post rest, differences were $7.98 \mathrm{~mm}$ for sensation and $7.89 \mathrm{~mm}$ for distress. Differences in pain were supported by significantly lower radial pulse rate on day 2 at rest, $P=0.004$, and observed respiration rate, $P=0.001-0.004$, in the treatment groups compared to the controls after each test.

\subsection{Mastery scores}

Before surgery, mean mastery scores were 7.66 during ambulation and 7.68 at rest, with 95 and $94 \%$ respectively, achieving mastery. Postoperatively, the range during ambulation was from 7.00 to 7.42 (SD $=0.75-1.07$ ) with 75 to $92 \%$ achieving mastery; at rest the range was from 7.27 to 7.47 (SD $=0.77-0.88$ ) with 84 to $92 \%$ achieving mastery. Repeated measures ANOVA indicated that mastery scores did not change differently over day 1 compared with day 2 , but did increase significantly from pretest to post-test during rest on day $1, F(1)=22.97, P=0.000$, and day $2, F(1)=$ $20.35, P=0.000$, and decreased significantly from post pre- paratory to post ambulation on day $1, F(1)=6.70, P=$ 0.001 , and day $2, F(1)=17.17, P=0.000$. Paired $t$-tests indicated that mastery scores returned to pretest levels after the recovery from ambulation period.

\section{Discussion}

In the first 2 painful days following major abdominal surgery, patients in the three treatment groups taken together had significantly less post-test pain than those in the control group at all data points during ambulation and rest. Further, multivariate analysis showed that each intervention resulted in less pain than the control group at every point except after ambulation for the relaxation group on both days, and for the music group on day 2 (Table 3). There were, however, some univariate effects for relaxation and music after ambulation, and pain in these two groups was effectively reduced during the preparation $(5 \mathrm{~min})$ and recovery $(10 \mathrm{~min})$ phases of ambulation, and during rest $(15 \mathrm{~min})$. In contrast, the combination group showed MV and UV effectiveness in 
Table 2

Contrast 1: multivariate and univariate analysis of covariance $(N=500)^{\mathrm{a}}$

\begin{tabular}{llllllllll}
\hline & \multicolumn{2}{l}{ Day 1} & & & & \multicolumn{2}{l}{ Day 2} & & \\
\cline { 2 - 3 } \cline { 5 - 7 } Post-tests & $F$ & df & $P$ & & $F$ & df & $P$ \\
\hline
\end{tabular}

\begin{tabular}{lrllrlrl}
\hline $\begin{array}{l}\text { Multivariate - pain } \\
\text { Ambulation }\end{array}$ & & & & & & \\
$\quad$ Post preparatory & 15.36 & 2,333 & 0.000 & 10.45 & 2,394 & 0.000 \\
Post ambulation & 5.63 & 2,333 & 0.002 & 2.90 & 2,394 & 0.028 \\
$\quad$ Post recovery & 5.43 & 2,333 & 0.003 & 5.15 & 2,394 & 0.003 \\
& & & & & & \\
Rest & & & & & & \\
$\quad$ Post rest & 11.19 & 2,451 & 0.000 & 22.23 & 2,436 & 0.000
\end{tabular}

$\begin{array}{lrllrll}\begin{array}{l}\text { Univariate - sensation } \\ \text { Ambulation }\end{array} & & & & & & \\ \quad \text { Post preparatory } & 22.34 & 1,339 & 0.000 & 20.14 & 1,400 & 0.000 \\ \quad \text { Post ambulation } & 4.50 & 1,339 & 0.018 & 5.61 & 1,400 & 0.009 \\ \text { Post recovery } & 10.14 & 1,339 & 0.001 & 11.82 & 1,400 & 0.001 \\ & & & & & & \\ \text { Rest } & & & & & & \\ \quad \text { Post rest } & 21.70 & 1,457 & 0.000 & 34.16 & 1,442 & 0.000\end{array}$

Univariate - Distress

Ambulation

$\begin{array}{lllllll}\text { Post preparatory } & 27.88 & 1,339 & 0.000 & 16.32 & 1,400 & 0.000\end{array}$

$\begin{array}{lllllll}\text { Post ambulation } & 10.66 & 1,339 & 0.001 & 5.18 & 1,400 & 0.012\end{array}$

$\begin{array}{lllllll}\text { Post recovery } & 10.56 & 1,339 & 0.001 & 6.08 & 1,400 & 0.007\end{array}$

Rest

$\begin{array}{lllllll}\text { Post rest } & 16.27 & 1,457 & 0.000 & 43.64 & 1,442 & 0.000\end{array}$

${ }^{a}$ Note, only contrast 1 is shown. It compares the three treatment groups taken together to the control group. Contrasts 2 and 3 were not given because only one of the tests was significant. Contrast 2 at Day 1 rest was significant on multivariate, $F(2,451)=2.96, P=0.027$, and univariate post-hoc tests for sensation, $F(1,453)=3.01, P=0.042$, and distress, $F(1,453)=5.60, P=0.009$.

all phases of ambulation and rest. In addition, there was a graded effect at Day 1 rest with the combination group having significantly less pain than the relaxation and music groups taken together. Mastery scores in this study were related to activity, significantly increasing during rest and decreasing during ambulation. Reminders to focus on the tape may improve effectiveness during ambulation. Health care professionals who prepare patients for surgery are encouraged to discuss the importance of managing the pain with relaxation, music and the combination, encouraging patient choice between the modalities. We emphasize that all the interventions were effective for sensation as well as distress, refuting the notion that these methods reduce only distress (McCaffery and Beebe, 1989).

\subsection{Support of theory}

The Good and Moore (1996) pain management theory comprises three propositions stating that multimodal therapy, attentive care and patient education are needed for control of acute pain. The results of this study support their multimodal proposition that non-pharmacological adjuvants along with analgesic medications reduce pain more than medications alone. Relaxation, music and their combination reduced pain more than PCA at ambulation and rest on the first 2 postoperative days. The mechanism of this effect can probably be best explained by the gate control theory: the perception of pain is decreased via 'gates', which are numerous and diverse points of filtration, abstraction and modulation of noxious input in the central nervous system. The gates are influenced by cognitive and emotional factors through descending inhibition systems (Melzack, 1982; Noordenbos, 1984; Jones, 1992).

The effect may occur through distraction, reduction of tension and sympathetic modulation. When relaxation and music distract the mind, the result is selective attention mediated by the thalamus that alerts the prefrontal cortex to the sound rather than to the painful input (Fuster and Alexander, 1973; Willis, 1985), causing pain inhibition (Fuster, 1980; Hardy, 1985). Relaxation and soothing music reduce muscular and mental tension and thereby, reduce sympathetic stimulation of the hypothalamus (Beary and Benson, 1974; Melzack, 1982; Turner and Chapman, 1982; Standley, 1986) which activates endogenous opiates in the central nervous system, reducing propagation of pain impulses and modulating perception of the sensory and affective components of pain (Vidal and Jacob, 1980; Carr and Uysal, 1985; Goldstein, 1985; Tasher et al., 1987; Culhane and Carstens, 1988). Concurrent reductions in pulse and respiration in this study indicate that relaxation or distraction reduces sympathetic activity as they reduce pain. In addition, music is known to stimulate the sensory cortex and the thalamus which have been found to inhibit nociceptive neurons in the spinal cord (Vidal and Jacob, 1980; Andy, 1983; Dickenson, 1983; Yezierski et al., 1983), and has been found to increase immune factors (Lane and Olness, 1991).

Sears and Carroll (1998) have questioned the clinical significance of small differences between relaxation and control groups in pain studies. However, studies of acute pain have large standard deviations due to differences in patient responses to pain and analgesics (Tamsen et al., 1982); these tend to diminish the mean effect. Differences in pain of 4-0 $\mathrm{mm}$ found in this study are clinically significant, since relaxation, music and the combination consistently reduced both sensation and distress, two components of pain endured by patients; and also reduced heart and respiratory rates moderating sympathetic nervous system activity. Therefore, listening to the tapes for longer periods of time postoperatively may have significant cumulative effects on stress and recovery. The effect was not confounded by strong opioid analgesics or by memory errors associated with a retrospective pain measures; pain was appropriately measured at the time it occurred (Feine et al., 1998). However, after the last test on day 2, subjects were asked to report the amount of relief provided by the intervention, and $84 \%$ said it reduced their pain a moderate 
Table 3

Post-hoc analysis of covariance $(N=500)^{\mathrm{a}}$

\begin{tabular}{|c|c|c|c|c|c|c|c|c|c|}
\hline \multirow[t]{2}{*}{ Post-tests } & \multicolumn{3}{|c|}{ Relaxation versus control } & \multicolumn{3}{|c|}{ Music versus control } & \multicolumn{3}{|c|}{ Combination versus control } \\
\hline & $F$ & df & $P$ & $F$ & df & $P$ & $F$ & df & $P$ \\
\hline \multicolumn{10}{|c|}{ Multivariate post-hoc tests - Wilks $F$ test } \\
\hline \multicolumn{10}{|c|}{ Day 1} \\
\hline Post preparatory & 12.60 & 2,333 & 0.000 & 8.97 & 2,333 & 0.000 & 9.43 & 2,333 & 0.000 \\
\hline Post ambulation & 2.15 & 2,333 & n.s.* & 5.36 & 2,333 & 0.003 & 4.33 & 2,333 & 0.007 \\
\hline Post recovery & 4.57 & 2,333 & 0.006 & 3.78 & 2,333 & 0.012 & 3.20 & 2,333 & 0.021 \\
\hline Post rest & 4.65 & 2,451 & 0.005 & 6.56 & 2,451 & 0.001 & 13.05 & 2,451 & 0.000 \\
\hline \multicolumn{10}{|l|}{ Day 2} \\
\hline Post preparatory & 7.09 & 2, 394 & 0.001 & 7.22 & 2, 394 & 0.001 & 6.66 & 2,394 & 0.001 \\
\hline Post ambulation & 1.03 & 2,394 & n.s. $* *$ & 2.17 & 2,394 & n.s. $* * *$ & 3.92 & 2,394 & 0.011 \\
\hline Post recovery & 3.16 & 2,394 & 0.022 & 3.44 & 2,394 & 0.017 & 3.82 & 2,394 & 0.012 \\
\hline Post rest & 15.32 & 2,436 & 0.000 & 14.44 & 2,436 & 0.000 & 15.57 & 2,436 & 0.000 \\
\hline \multicolumn{10}{|c|}{ Univariate - sensation } \\
\hline \multicolumn{10}{|c|}{ Day 1} \\
\hline Pre ambulation & 21.84 & 1,339 & 0.000 & 13.04 & 1,339 & 0.000 & 10.36 & 1,339 & 0.001 \\
\hline Post ambulation & 0.90 & 1,339 & n.s. $* * * *$ & 6.02 & 1,339 & 0.008 & 3.14 & 1,339 & 0.035 \\
\hline Post recovery & 7.10 & 1,339 & 0.004 & 8.14 & 1,339 & 0.003 & 5.02 & 1,339 & 0.013 \\
\hline Post rest & 8.02 & 1,457 & 0.003 & 14.93 & 1,457 & 0.000 & 22.63 & 1,457 & 0.000 \\
\hline \multicolumn{10}{|l|}{ Day 2} \\
\hline Pre ambulation & 12.77 & 1,400 & 0.000 & 14.99 & 1,400 & 0.000 & 11.86 & 1,400 & 0.001 \\
\hline Post ambulation & 0.51 & 1,400 & n.s. ${ }^{\dagger}$ & 5.04 & 1,400 & 0.013 & 7.77 & 1,400 & 0.003 \\
\hline Post recovery & 6.99 & 1,400 & 0.005 & 7.47 & 1,400 & 0.004 & 8.79 & 1,400 & 0.002 \\
\hline Post rest & 19.13 & 1,442 & 0.000 & 24.27 & 1,442 & 0.000 & 25.73 & 1,457 & 0.000 \\
\hline \multicolumn{10}{|c|}{ Univariate - distress } \\
\hline \multicolumn{10}{|c|}{ Day 1} \\
\hline Pre ambulation & 20.79 & 1,339 & 0.000 & 16.05 & 1,339 & 0.000 & 18.12 & 1,339 & 0.000 \\
\hline Post ambulation & 3.31 & 1,339 & 0.035 & 10.82 & 1,339 & 0.001 & 8.03 & 1,339 & 0.003 \\
\hline Post recovery & 9.19 & 1,339 & 0.002 & 5.43 & 1,339 & 0.010 & 6.40 & 1,339 & 0.006 \\
\hline Post rest & 7.66 & 1,457 & 0.003 & 6.31 & 1,457 & 0.006 & 21.32 & 1,457 & 0.000 \\
\hline \multicolumn{10}{|l|}{ Day 2} \\
\hline Pre ambulation & 11.71 & 1,400 & 0.001 & 9.42 & 1,400 & 0.001 & 10.95 & 1,400 & 0.001 \\
\hline Post ambulation & 1.58 & 1,400 & n.s. ${ }^{\dagger \dagger}$ & 2.71 & 1,400 & n.s. ${ }^{\dagger \dagger \dagger}$ & 6.84 & 1,400 & 0.005 \\
\hline Post recovery & 4.13 & 1,400 & 0.022 & 5.13 & 1,400 & 0.012 & 2.85 & 1,400 & 0.046 \\
\hline Post rest & 30.98 & 1,442 & 0.000 & 27.02 & 1,442 & 0.000 & 29.76 & 1,442 & 0.000 \\
\hline
\end{tabular}

${ }^{a}$ Note, only the differences between each treatment group and the controls are shown. Day 1 rest multivariate post-hoc differences were not significant between the combination group versus the relaxation or the music group, $F(2,226)=1.88, P=0.08$. Day 1 rest univariate differences did not confirm the MV tests. Compared with the relaxation group, the combination group had significantly less sensation, $F(1,228)=3.75, P=0.027$, and less distress, $F(1$, $222)=3.84, P=0.026$. Compared with the music group, the combination had significantly less distress, $F(1,222)=4.06, P=0.023$, but the lower sensation scores were not significantly different.

$* P=0.059 ; * * P=0.147 ; * * * P=0.058 ; * * * *=0.172,{ }^{\dagger} P=0.238$; ${ }^{\dagger \dagger} P=0.105 ;{ }^{\dagger \dagger} P=0.051$; n.s., not significant.

amount or a lot; this may have been an overestimation for some of the four tests. However, these general perceptions of relief at the exit interview do add support to the high satisfaction with the interventions, that is, nearly all $(91 \%)$ said they would use a tape like this again if in pain, and $96 \%$ would recommend it to others for surgery.

\subsection{Comparison to other studies}

\subsubsection{Ambulation}

These results are in sharp contrast to those of Good (1995) $(n=21)$, who found at initial ambulation that none of these tapes reduced sensation, distress, or anxiety of pain after return to bed, although they were reported helpful during the next 2 days. In the present study, with the same tapes and comparisons, but with a larger sample at subsequent ambulations we found that the combination on both days, and music on day 1 reduced pain, significantly more than usual care at all three points: after preparation, after ambulation and after recovery (Table 3 ), with mixed results after ambulation for music on day 2 and for relaxation on day 1 .

In contrast to the present study, most investigations of the effects of jaw relaxation on pain during ambulation were 
conceptualized and analyzed univariately, therefore making comparisons complex. Ceccio (1984) $(n=10)$ found that jaw relaxation reduced both components of pain after initial turning, but Mogan et al. (1985) $(n=40)$ found relaxation reduced only distress after ambulation; two others had positive or negative results, respectively, but did not randomize, or provide pretest control (Flaherty and Fitzpatrick, 1978; $n=21$; Horowitz et al., 1984; $n=15$ ). Inconsistent results may be due to small samples and methodological problems.

\subsubsection{Rest}

The three interventions together reduced multivariate pain, significantly more than the controls at rest on both days (Table 2). In addition, there was a graded effect: the combination treatment was significantly more effective than the individual interventions at day 1 rest. The post-hoc UV findings at rest were similar to (Levin et al., 1987) who used Benson's relaxation technique, (Locsin, 1981, 1988) who used preferred music to reduce pain behavior, and Mullooly et al. (1988) ( $n=11)$, who used easy listening music and found effects for both components of pain on day 2, and only for distress on day 1 . Group sizes of $>100$ (Table 1) were probably the reason the findings were more positive than those in small preliminary studies. Several investigators found the interventions reduced only the affective component of pain at rest (Mogan et al., 1985; $n=40$; Wells, 1982; $n=6$; Wilson, $1981 ; n=18$ ) or music reduced different pain components on different days (Good and Chin, 1998; $n=16$ ), or had no significant results for relaxation (Voshall, 1980; $n=15$ ); or for music in the recovery room (Heitz et al., 1992; $n=20$ ) (Heiser et al., 1997; $n=5$ ) or following cardiac surgery (Zimmerman et al., 1996; $n=26$ ). In future studies, relationships between duration of use, relief and occurrence of side effects and complications should be explored, along with effects of relief on stress and immune responses. These interventions should be tested with other kinds of pain: chronic, cancer and procedural pain across age groups, and in the critically ill.

In conclusion, these data strongly support recommendations by the Acute Pain Management Guideline Panel (1992) to add non-pharmacological interventions, such as relaxation, music, or their combination to pharmacological treatment of pain during ambulation and at rest on postoperative days 1 and 2 . Both sensation and distress were significantly reduced, and these results were not confounded by opioids. Greater effectiveness was demonstrated for the relaxation and music combined over the individual interventions at day 1 rest, but patient preference may be important as well. Control of postoperative pain with these interventions after major surgery may also reduce opioid side effects and may hasten recovery.

\section{Acknowledgements}

We thank Richard Zeller, PhD, statistical consultant for the study, and Ada Jacox, PhD, pain management consultant. We also thank Linda Schuler, project manager, and her team of clinical research nurses for clinical implementation of the interventions: Vivian Balzar, Cynthia DiFranco, Debbie Donohue, Carol Duber, Jennifer Geras, Tonya Halfhill, Aisha Ja'far-Bey, Jo Anne Rhoads, Barbara Sedenski, Catherine Stiller, Sandra Siedlecki, Arleen Sudyk, Suzanne Vendlinski, and Jane Wixted. The study was supported by the National Institute of Nursing Research, NIH, Grant Number RO1 NR-03933 (1994-1998), to M.G., principal investigator.

\section{References}

Acute Pain Management Guideline Panel, Acute pain management: operative or medical procedures and trauma. Clinical practice guideline, Agency for Health Care Policy and Research, Public Health Service, US Department of Health and Human Services, Vol. AHCPR No. 920032, Rockville, MD, 1992.

Andy, O.J., Thalamic stimulation for chronic pain, Appl. Neurophysiol., 46 (1983) 116-123.

Beary, B. and Benson, H., A simple psychophysiological technique which elicits the hypometabolic changes in relaxation response, Psychosom. Med., 36 (1974) 115-120.

Blankfield, R.P., Suggestion, relaxation, and hypnosis as adjuncts in the care of surgery patients: a review of the literature, Am. J. Clin. Hypn., 33 (1991) 172-186.

Bonica, J.J., Current status of postoperative pain theory. In: J.Y.R. Dubner (Ed.), Current Topics in Pain Research and Therapy, Excerpta Medica, Tokyo, 1983, pp. 169-189.

Borkovec, T.D. and Sides, J.K., Critical procedural variables related to the psychological effects of progressive relaxation: a review, Behav. Res. Ther., 17 (1979) 119-125.

Carr, K.D. and Uysal, S., Evidence of supraspinal opioid analgesic mechanism engaged by lateral hypothalamic electrical stimulation, Brain Res., 335 (1985) 55-62.

Ceccio, C.M., Postoperative pain relief through relaxation in elderly patients with fractured hips, Orthop. Nurs., 3 (1984) 11-14.

Chapman, C.R., Psychological factors in postoperative pain. In: G. Smith and B.G. Covino (Eds.), Acute Pain, Butterworths, London, 1985, pp. $22-41$.

Cook, T.D. and Campbell, D.T., Quasi-Experimentation: Design and Analysis Issues for Field Settings, Houghton Miller, Boston, MA, 1979.

Culhane, E.S. and Carstens, E., Medial hypothalamic stimulation suppresses nociceptive spinal dorsal horn neurons but not the tail-flick reflex in the rat, Brain Res., 438 (1988) 374-381.

Dickenson, A., The inhibitory effects of thalamic stimulation on the spinal transmission of nociceptive information in the rat, Pain (1983) 213224.

Everitt, B.S. and Dunn, G., Applied Multivariate Data Analysis, Halstead Press, New York, 1991.

Feine, J.S., Lavigne, G.J., Thuan Dao, T.T., Morin, C. and Lund, J.P., Memories of chronic pain and perceptions of relief, Pain, 77 (1998) 137-141.

Flaherty, G.G. and Fitzpatrick, J.J., Relaxation technique to increase comfort level of postoperative patients: a preliminary study, Nurs. Res., 27 (1978) 352-355.

Fuster, J.H., Prefrontal Cortex Stimulation Results in Pain Inhibition, The Prefrontal Cortex, Raven Press, New York, 1980.

Fuster, J.H. and Alexander, G.E., Firing changes in cells of nucleus medialis dorsalis associated with delayed response behavior, Brain Res., 61 (1973) 79-81.

Goldstein, A., Music/endorphin link, Brain/Mind Bull., 11 (1985) 1. 
Good, M., A comparison of the effects of jaw relaxation and music on postoperative pain, Nurs. Res., 44 (1995) 52-57.

Good, M., Effects of relaxation and music on postoperative pain: a review, J. Adv. Nurs., 24 (1996) 905-914.

Good, M. and Moore, S.M., Clinical practice guidelines as a new source of middle-range theory: focus on acute pain, Nurs. Outlook, 44 (1996) 7479.

Good, M. and Chin, C., The effects of Western music on postoperative pain in Taiwan, Kaoshiung Med. J., 14 (1998) 93-103.

Hanser, S.B., Larson, S.C. and O'Connell, A.S., The effect of music on relaxation of expectant mothers during labor, J. Music Ther., 20 (1983) 50-58.

Hardy, S.G.P., Analgesia produced by prefrontal stimulation, Brain Res., 339 (1985).

Heiser, R.M., Chiles, K.C., Fudge, M. and Gray, S.E., The use of music during the immediate post-operative recovery period, AORN, 65 (1997) $777-785$

Heitz, L., Symreng, T. and Scamman, F.L., Effect of music therapy in the postanesthesia care unit: a nursing intervention, J. Post Anesth. Nurs., 7 (1992) 22-31.

Henry, L.L., Music therapy: a nursing intervention for the control of pain and anxiety in the ICU: a review of the research literature, Dimens. Crit. Care Nurs., 16 (1995) 295-304.

Horowitz, B., Fitzpatrick, J.J. and Flaherty, G., Relaxation techniques for pain relief after open heart surgery, Dimens. Crit. Care Nurs., 3 (1984) $364-371$.

Johnson, J.E., Effects of accurate expectations about sensations on the sensory and distress components of pain, J. Pers. Soc. Psychol. (1973) 261-275.

Jones, J.G., Historical overview of pain management: undermedication to state of the art. In: R.S. Sinatra, A.H. Hord, B. Ginsberg and L.M. Preble (Eds.), Acute Pain: Mechanisms and Management, Mosby Yearbook, St. Louis, MO, 1992.

Lane, D. and Olness, K., Effect of music therapy on salivary immunoglobulin A levels in children, Pediatr. Res., 29 (2) (1991) 11.

Lawlis, G.F., Selby, D., Hinnant, D. and McCoy, C.E., Reduction of postoperative pain parameters by presurgical relaxation instructions for spinal pain patients, Spine, 10 (1985) 649-651.

Levin, R.F., Malloy, G.B. and Hyman, R.B., Nursing management of postoperative pain: use of relaxation techniques with female cholecystectomy patients, J. Adv. Nurs., 12 (1987) 463-472.

Livingston, J.C., Music for the childbearing family, J. Obstet. Gynecol. Neonatal Nurs., 8 (1979) 363-367.

Locsin, R., The effect of music on the pain of selected post-operative patients, J. Adv. Nurs., 6 (1981) 19-25.

Locsin, R., Effects of preferred music and guided imagery music on the pain of selected postoperative patients, ANPHI Papers, 23 (1988) 2-4.

McCaffery, M. and Beebe, A., Pain: Clinical Manual for Nursing Practice, CV Mosby, St. Louis, MO, 1989.

Melzack, R., The McGill Pain Questionnaire: major properties and scoring methods, Pain, 1 (1975) 277-299.
Melzack, R., Recent concepts of pain, J. Med., 13 (1982) 147-160.

Miaskowski, C., Current concepts in the assessment and management of acute pain., Med. Surg. Nurs., 2 (1993) 28-32.

Miller, K.M. and Perry, P.A., Relaxation technique and postoperative pain in patients undergoing cardiac surgery, Heart Lung, 19 (1990) 136-146.

Mogan, J., Wells, N. and Robertson, E., Effects of preoperative teaching on postoperative pain: a replication and expansion, Int. J. Nurs. Stud., 22 (1985) 267-280

Mullooly, V.M., Levin, R.F. and Feldman, H.R., Music for postoperative pain and anxiety, J. N.Y. State Nurs. Assoc., 19 (1988) 4-7.

Noordenbos, W., Prologue. In: P.D. Wall and R. Melzak (Eds.), Textbook of Pain, Churchill Livingstone, New York, 1984.

Sears, K. and Carroll, D., Relaxation techniques for acute pain management: a systematic review, J. Adv. Nurs., 27 (1998) 466-475.

Standley, J.M., Music research in medical/dental treatment: meta-analysis and clinical applications, J. Music Ther., 23 (1986) 56-122.

Stevenson, C., Non-pharmacological aspects of acute pain management, Compl. Ther. Nurs. Midwifery, 1 (1995) 77-84.

Tamsen, A., Hartvig, P., Fagerlund, C. and Dahlstrom, B., Patient-controlled analgesic therapy, part II: individual analgesic demand and analgesic plasma concentrations of pethidine in postoperative pain, Clin. Pharmacokinet., 7 (1982) 164-175.

Tasher, R.A.R., Choiniere, M., Libman, S.M. and Melzack, R., Analgesia produced by injection of lidocaine into lateral hypothalamus, Pain, 31 (1987) 237-248.

Turner, J.A. and Chapman, C.R., Psychological interventions chronic pain: a critical review. II. Operant conditioning, hypnosis, and cognitivebehavioral therapy, Pain, 12 (1982) 23-46.

Vidal, C. and Jacob, J., The effect of medial hypothalamic lesions on pain control., Brain Res., 199 (1980) 89-104.

Voshall, B., The effects of preoperative teaching on postoperative pain. In: Z.R. Wolf (Ed.), Topics of Clinical Nursing: Pain Management, Aspen Systems Corporation, Frederick, MD, 1980.

Weis, O.F., Sriwatanakul, K., Alloza, J.L., Weintraub, M. and Lasagna, L., Attitudes of patients, housestaff, and nurses toward postoperative analgesic care, Anesthesia and Analgesia, 62 (1983) 70-74.

Wells, N., The effect of relaxation on postoperative muscle tension and pain, Nurs. Res., 31 (1982) 236-238.

Willis, W.D., The Pain System, Basel, Karger, 1985.

Wilson, J.F., Behavioral preparation for surgery: benefit or harm? J. Behav. Med., 4 (1981) 79-102.

Yezierski, R.P., Gerhart, K.D., Schrock, B.J. and Willis, W.D., A further examination of effects of cortical stimulation on primate spinothalmic tract cells, J. Neurophysiol., 49 (1983) 424-441.

Zeller, R., Good, M., Anderson, G.C. and Zeller, D., Strengthening experimental design by balancing confounding variables across eight treatment groups, Nurs. Res., 46 (1997) 345-349.

Zimmerman, L., Nieveen, J., Barnason, S. and Schmaderer, M., The effects of music interventions on postoperative pain and sleep in coronary artery bypass graft (CABG) patients., Sch. Inq. Nurs. Pract., 10 (1996) 153-174. 